\title{
Liga ou Desliga? Um software educacional para o aprendizado de Sistemas Digitais
}

\author{
Fabrizio Honda Franzoia ${ }^{1}$, Almir de Oliveira Costa Junior ${ }^{1}$ \\ ${ }^{1}$ Universidade do Estado do Amazonas - Escola Superior de Tecnologia (UEA/EST) - \\ Manaus - AM - Brasil \\ \{fhf.lic17, adjunior\}@uea.edu.br
}

\begin{abstract}
Resumo. Considerando a necessidade do século XXI de profissionais capacitados para solucionar problemas de forma criativa, e além disso, o impacto dos Circuitos Digitais na sociedade, o presente trabalho descreve o processo de desenvolvimento de uma ferramenta para lousa digital denominada "Liga ou Desliga?", que objetiva auxiliar no aprendizado de Circuitos Digitais através de uma mecânica prática para exercitar o tema, no qual o usuário relaciona portas lógicas e entradas para indicar as saídas corretas.
\end{abstract}

\section{Cenários de Uso}

Os crescentes avanços tecnológicos trouxeram consigo uma série de mudanças para a sociedade, exigindo profissionais capacitados, críticos e criativos, que busquem pelas melhores soluções para problemas e adaptam-se rapidamente às frequentes mudanças (Santos \& Costa, 2006; Silva \& Cunha, 2002). Essas são algumas das características do profissional de Computação/TI, que constantemente está a frente de uma diversidade de situações, necessitando de um bom raciocínio lógico para lidar com estas.

Contudo, há uma dificuldade no cenário brasileiro em cursos de Computação/TI, dos quais seus índices de evasão estão entre os maiores (Marques et al., 2011). Nestes cursos, caso o estudante não consiga desenvolver seu raciocínio lógico, isto pode atrapalhar seu desempenho em disciplinas como Circuitos Digitais, que exige bastante desta competência (Neto et al., 2018). Os Circuitos Digitais estão presentes na sociedade em diversos segmentos, sendo estes essenciais para a fabricação de computadores e dispositivos como telefones e videogames. Além disso, estão presentes em máquinas de atendimento automático, leitoras de cartão de crédito, etc. (Vahid, 2009).

Nesse contexto, a proposta deste trabalho é apresentar o processo de desenvolvimento de um software educacional denominado "Liga ou Desliga?" que tem como objetivo principal auxiliar no processo de aprendizagem de Circuitos Digitais por meio de atividades práticas sobre o tema.

\section{Desenvolvimento}

A ferramenta foi desenvolvida através da engine para desenvolvimento de jogos Unity versão 2018.3.3f1, com códigos-fonte na linguagem de programação orientada a objetos C\#. Para a construção da ferramenta, seguiu-se uma série de etapas, fundamentadas no modelo Incremental de Fuks et al. (2003) e adaptadas a partir dos processos de 
VIII Congresso Brasileiro de Informática na Educação (CBIE 2019)

Anais dos Workshops do VIII Congresso Brasileiro de Informática na Educação (WCBIE 2019)

desenvolvimento de trabalhos como os de Melo et al. (2018) e David et al. (2018), que podem ser visualizadas a partir do seguinte diagrama (Figura 01):

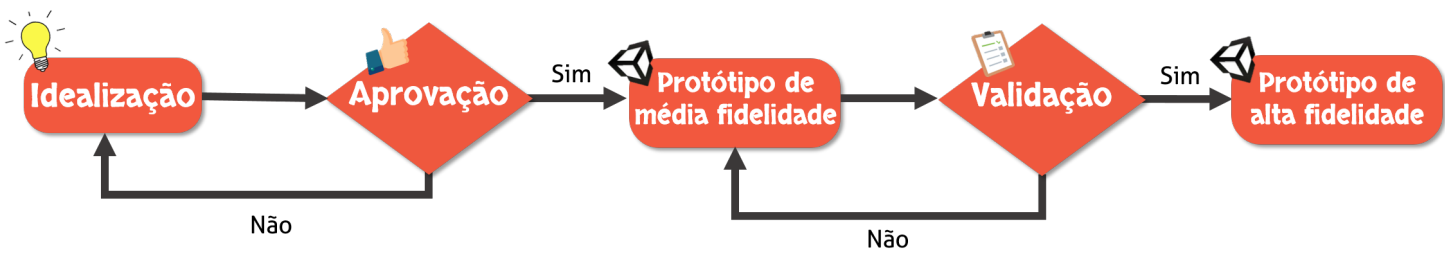

Figura 01. Diagrama dos processos de desenvolvimento

\subsection{Idealização}

Esta é a primeira etapa do processo de desenvolvimento, que se caracterizou pela definição de tópicos primordiais da ferramenta. Dentre estes: a escolha do público-alvo, a(s) disciplina (s) de aplicação da ferramenta, o conteúdo específico abordado, o estabelecimento das mecânicas, esboços iniciais do design e a navegabilidade usuárioferramenta.

\subsection{Aprovação}

A aprovação consistiu de diversas análises da ferramenta, com o intuito de viabilizá-la para a etapa seguinte. Desta forma, foram indicados pontos de melhoria, sugestões de modificações e correções necessárias a serem realizadas. A partir deste feedback, retornou-se para a etapa anterior e esse processo continuou até que a ferramenta fosse definitivamente aprovada.

\subsection{Protótipo de média fidelidade}

Esta etapa teve por objetivo realizar a construção das primeiras versões da ferramenta. A parte visual, foi produzida através do 'Adobe Photoshop' e 'PowerPoint'. A mecânica e navegabilidade idealizadas anteriormente foram implementadas no Software de desenvolvimento de jogos Unity.

\subsection{Validação}

Similar ao processo de aprovação, a validação objetivou analisar a ferramenta sob uma perspectiva de seu funcionamento e possíveis sobrecargas visuais. Caso a ferramenta necessitasse de alterações consideráveis, tais como: i - mecânica não condizente com o objetivo, ii - interface não adaptada para utilização na lousa digital, o processo anterior deveria ser retomado para que fosse realizada modificações no protótipo. Em "Liga ou Desliga?" a validação foi positiva, seguindo para a próxima etapa.

\subsection{Protótipo de alta fidelidade}

A produção da versão final da ferramenta deu-se nesta etapa, na qual os últimos ajustes foram implementados, tornando-a funcional e de acordo com suas características idealizadas. 
VIII Congresso Brasileiro de Informática na Educação (CBIE 2019)

Anais dos Workshops do VIII Congresso Brasileiro de Informática na Educação (WCBIE 2019)

\section{Apresentação do software}

"Liga ou Desliga?" é um software para lousa digital que envolve conceitos, fundamentos e a representação do funcionamento de um Sistema Digital. O usuário tem como objetivo, concluir as diversas fases da ferramenta, preenchendo corretamente a saída de cada porta lógica dos Sistemas Digitais presentes, mediante interação com a lousa digital. O requisito mínimo para executar o jogo é: sistema operacional Windows.

A ferramenta instiga o usuário, através da ludicidade e de mecânicas simples, a exercitar seu conhecimento sobre Sistemas Digitais e proporciona uma forma prática de "fixar" este tema, dispondo de noções essenciais, tais como: entrada e saída de dados, portas lógicas, operações booleanas (and/or/not), tabela verdade e representação binária. A ferramenta tem como público-alvo, estudantes que estejam cursando disciplinas de 'Organização e Arquitetura de Computadores', 'Circuitos Digitais' ou a qualquer pessoa interessada em compreender Sistemas Digitais. A Figura 02 contém o fluxo de telas da ferramenta. Através do link https://youtu.be/BRda9kNj2zg é possível assistir a um vídeo demonstrativo com a gameplay da ferramenta.

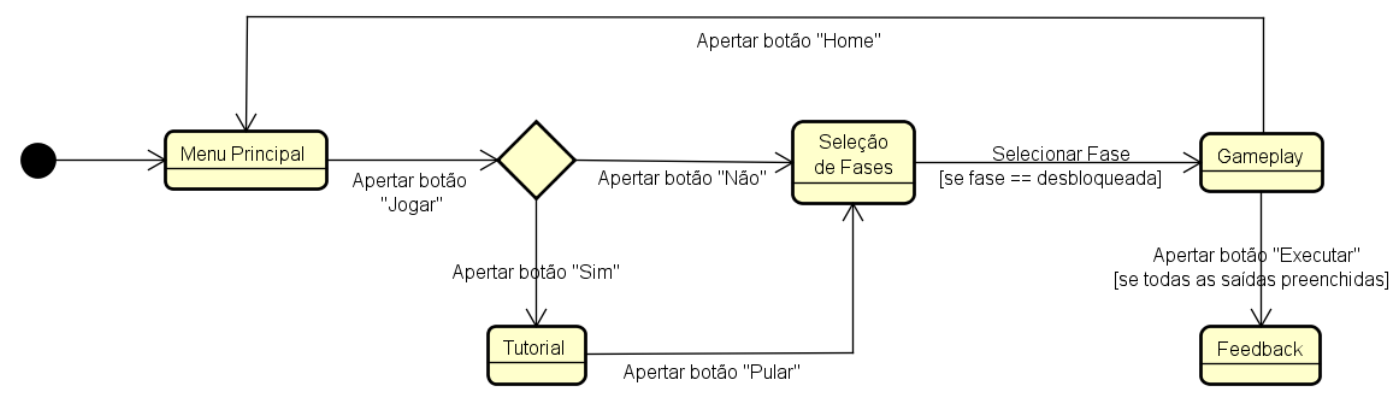

Figura 02. Fluxo de Telas da Ferramenta

\subsection{Mecânica da ferramenta}

A mecânica da ferramenta baseia-se no funcionamento de um Sistema Digital. Este possui três componentes essenciais: entradas, portas lógicas e saídas (Figura 03).

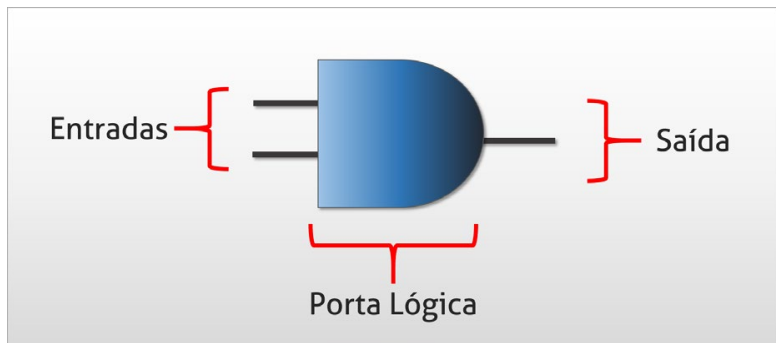

Figura 03. Componentes essenciais de um Sistema Digital

i) Entradas: são os valores - verdadeiros (1) ou falsos (0) - que uma porta lógica receberá, representados na ferramenta por lâmpadas ligadas e desligadas, respectivamente. Em cada fase, estas lâmpadas (entradas) acompanham uma letra do 
VIII Congresso Brasileiro de Informática na Educação (CBIE 2019)

Anais dos Workshops do VIII Congresso Brasileiro de Informática na Educação (WCBIE 2019)

alfabeto (Figura 04). Exemplificando, uma lâmpada desligada A indica que sua entrada é falsa e uma lâmpada desligada B verdadeira.

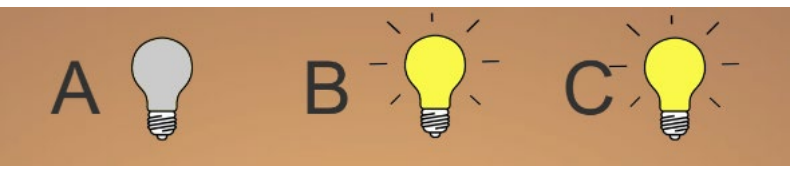

Figura 04. Valores das entradas

ii) Portas Lógicas e Saídas: as portas lógicas são relações/operações entre determinadas entradas, cada uma com sua particularidade, que resultam numa saída única de valor verdadeiro ou falso. Estas saídas podem ser entradas para outra porta lógica.

As saídas dependem da relação entre o tipo de porta lógica e dos valores das entradas. Essas relações podem ser observadas a partir das tabelas-verdade a seguir (Figura 05).

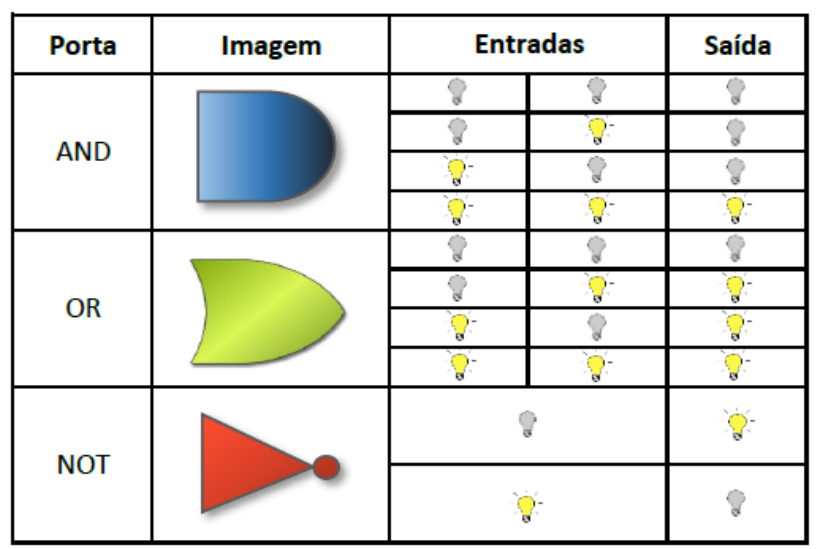

Figura 05. Tabela-verdade das portas lógicas

Ao abstrair essas tabelas-verdades, pode-se observar que: a porta $A N D$ resulta em lâmpada desligada (falso) se uma das lâmpadas da entrada estiver desligada; a porta $O R$ resulta em lâmpada ligada (verdadeiro) se uma das lâmpadas da entrada estiver ligada; a porta NOT inverte o valor da lâmpada. Estas informações são disponibilizadas, via tutorial, para o usuário poder utilizar a ferramenta.

Em cada fase da ferramenta, os valores das saídas das portas lógicas estão representados por botões de cor branca; quando apertados, revelam uma lâmpada desligada e apertando-os novamente, uma lâmpada ligada. O objetivo do usuário é preenchê-los com as lâmpadas corretas - de acordo com o tipo de porta lógica e dos valores das entradas - e apertar o botão "executar". Depois da realização destas ações, o usuário receberá um feedback positivo - se todas as saídas estiverem corretas - ou negativo - uma ou mais saídas incorretas. Pode ainda receber uma mensagem de erro, caso tenha deixado alguma saída em branco. Conforme a mecânica da ferramenta, a Figura 06 mostra a primeira fase (a) e sua resolução correta (b). 


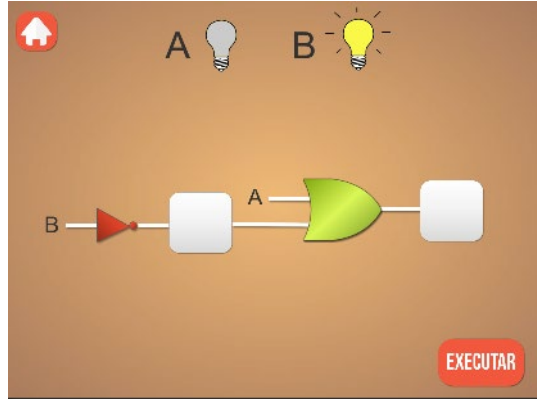

(a) Primeira Fase

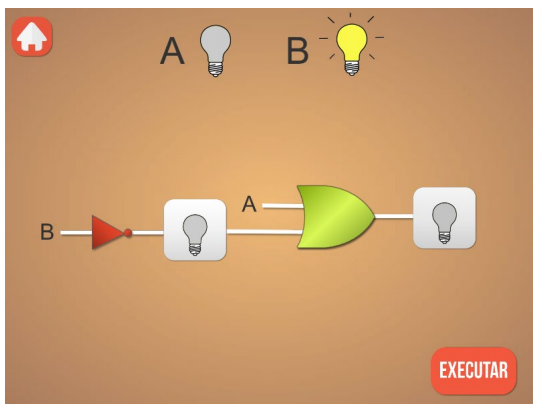

(b) Resolução correta da primeira fase

Figura 06. Primeira fase da ferramenta e sua resolução correta, respectivamente

Decompondo o Sistema Digital desta fase, têm-se: duas entradas A e B de valores falsos (lâmpada desligada) e verdadeiro (lâmpada ligada), duas portas lógicas $(O R$ e $N O T)$ e duas saídas. A resposta correta para as duas saídas são ambas lâmpadas desligadas: a primeira, pois a porta NOT inverte a lâmpada B de ligada para desligada; e a segunda, pois uma entrada falsa em uma porta lógica $O R$, resulta em falso.

\subsection{Descrição das Telas}

\section{Menu Principal}

Trata-se da primeira tela do jogo (Figura 07a). A partir dela, o jogador pode direcionarse as demais. Apertando o botão "play", surge um pop-up perguntando ao usuário se ele deseja ver um pequeno tutorial ou não (Figura 07b); em caso positivo, é direcionado à tela tutorial, caso contrário, à tela de fases.

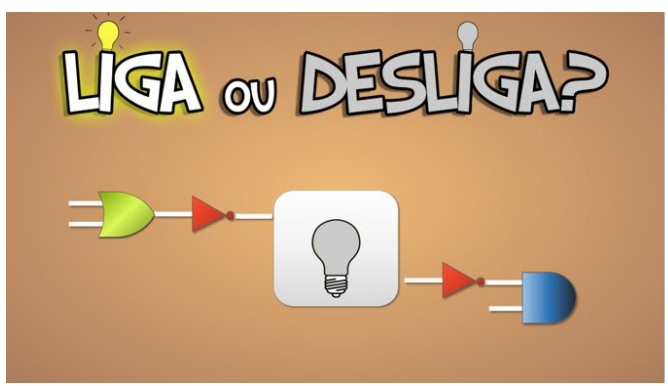

(a) Tela Principal

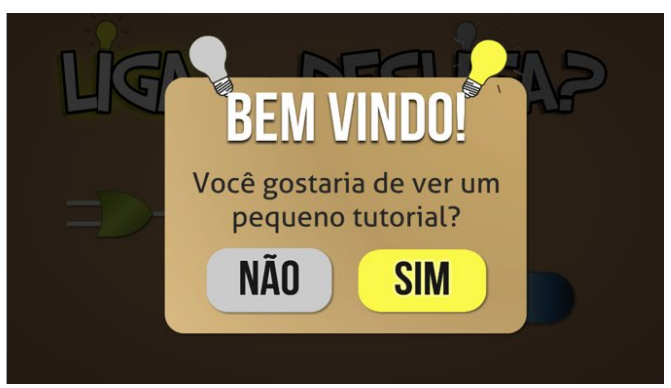

(b) Pop-up para acesso do tutorial

Figura 07. Tela Principal e Pop-up

\section{Tutorial}

É composto de um conjunto de quatro telas (Figura 08), apresentando conceitos essenciais ao usuário que este necessita abstrair para usufruir da ferramenta: 0's e 1's representados por lâmpadas ligadas e desligadas, definição, exemplo e operações de portas lógicas. $\mathrm{Na}$ última tela do tutorial está contido um pequeno exemplo para o usuário testar a mecânica da ferramenta. A partir do feedback gerado com a 'execução' do Sistema, é possível reiniciar o exemplo ou ir para a tela de Fases. 
VIII Congresso Brasileiro de Informática na Educação (CBIE 2019)

Anais dos Workshops do VIII Congresso Brasileiro de Informática na Educação (WCBIE 2019)

Os botões com setas apontadas para a direita avançam para a próxima tela do tutorial. Em qualquer uma destas telas, o usuário pode optar por seguir diretamente para a tela de fases, através do botão "Pular".
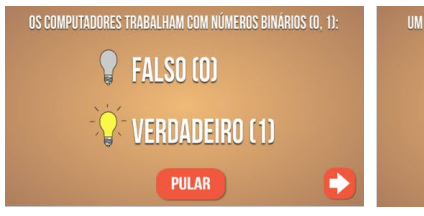
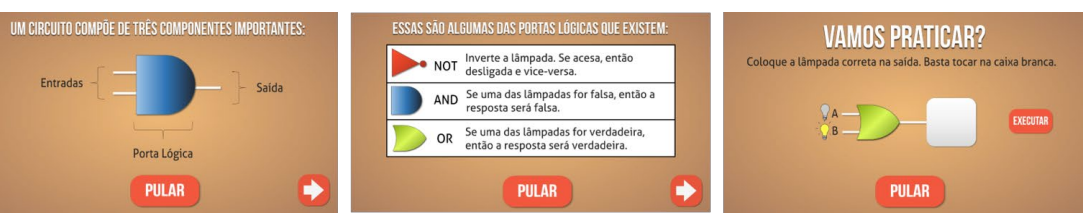

Figura 08. Telas do Tutorial

\section{Seleção de Fases}

A ferramenta possui um total de cinco fases, cada uma com um Sistema Digital e uma variedade de portas lógicas $A N D, O R$ ou NOT. Quanto maior o nível, maior a quantidade de portas lógicas, por consequência, maior o número de saídas que o usuário deverá preencher para prosseguir de fase. No primeiro contato com a ferramenta, o usuário pode utilizar apenas a primeira fase; para desbloquear as demais, precisa concluir a anterior. Nesta tela, os botões de cada fase estão numerados de 1 a 5 e representados por lâmpadas desligadas; no momento em que uma fase for concluída, a lâmpada que a representa torna-se ligada (Figura 09). Fases bloqueadas apresentam uma transparência maior que as outras, indicando a impossibilidade de acessá-las. Apertar em uma fase desbloqueada direciona o usuário para tela de 'gameplay' respectiva.
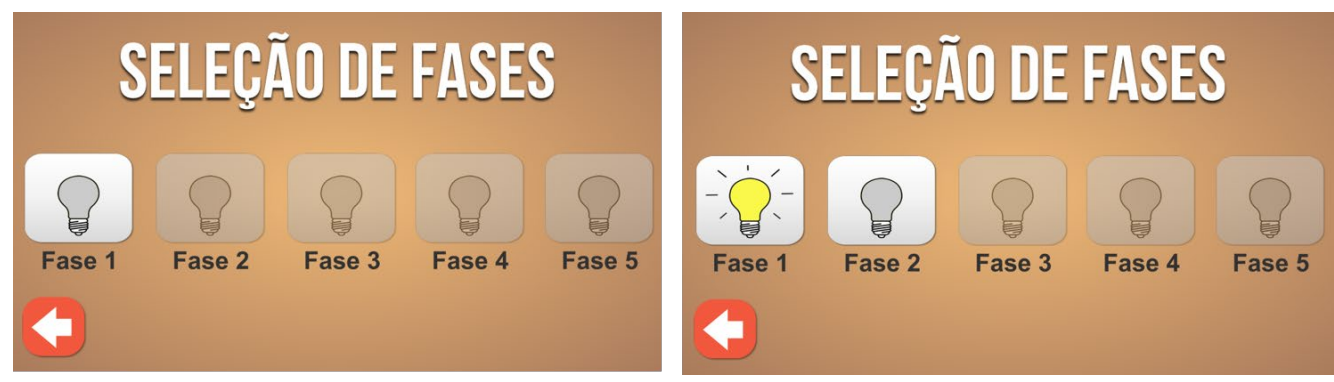

Figura 09. Telas de seleção de Fases

\section{'Gameplay'}

Esta é tela na qual o usuário pode interagir com os Sistemas Digitais de cada fase. Após resolvê-los e obter feedback, o usuário pode reiniciar a fase ou retornar à tela de seleção. O botão "próxima fase", entretanto, só aparece ao usuário caso este tenha obtido feedback positivo e se a fase não for a última. Caso haja uma saída não preenchida, uma mensagem de erro aparecerá.
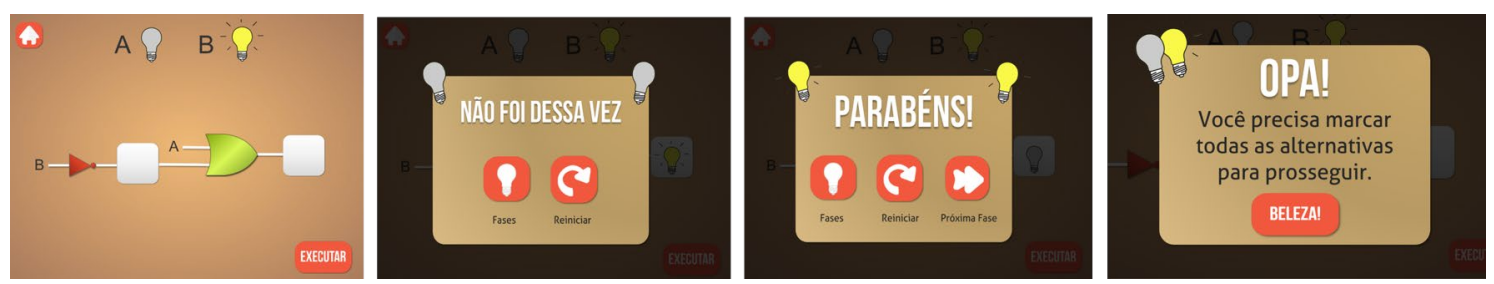
VIII Congresso Brasileiro de Informática na Educação (CBIE 2019)

Anais dos Workshops do VIII Congresso Brasileiro de Informática na Educação (WCBIE 2019)

\section{Figura 09. Telas de Gameplay, Feedbacks de derrota e vitória e mensagem de erro, respectivamente}

\section{Resultados esperados}

Pretende-se realizar testes de usabilidade e experiência de usuário com a ferramenta, para analisar possíveis mudanças - tanto em questões de visual quanto em suas mecânicas - e impactos na aprendizagem. Espera-se que a ferramenta contribua positivamente na aprendizagem do estudante, no que diz respeito aos conteúdos de Sistemas Digitais, e em seu interesse para com este tema.

\section{Considerações Finais}

A ferramenta "Liga ou Desliga?" possibilita ao usuário exercitar seus conhecimentos sobre Circuitos Digitais, de forma lúdica e interativa, por meio de uma mecânica simples, na qual o usuário relaciona entradas e portas lógicas e indica sua saída correta. Pretende-se, futuramente, aprimorar a ferramenta ainda mais, em design, mecânicas, acrescentar mais fases e aplicá-la em salas de aula.

\section{Referências}

David, W., Alencar, L., Duarte, J., \& de Sousa Pires, F. G. (2018). Tricô numérico: Um jogo para alfabetização matemática. Paper presented at the Anais dos Workshops do Congresso Brasileiro de Informática na Educação.

Fuks, H., Raposo, A. B., Gerosa, M. A., \& Lucena, C. J. P. J. S. B. d. S. M. e. W. W. (2003). Do modelo de colaboração 3c à engenharia de groupware. 0-8.

Marques, D. L., Costa, L. F. S., de Azevedo Silva, M. A., \& Rebouças, A. D. D. S. (2011). Atraindo alunos do ensino médio para a computação: Uma Experiência Prática de Introdução à Programação utilizando Jogos e Python. Paper presented at the Anais do Workshop de Informática na Escola.

Melo, D., Júnior, R. J. d. R. S., Duarte, J., \& de Sousa Pires, F. G. (2018). Robô Euroi: Estratégias Matemáticas para desenvolver o Pensamento Computacional. Paper presented at the Anais dos Workshops do Congresso Brasileiro de Informática na Educação.

Neto, A. C. A., da Silva, J. M., \& Sarinho, V. (2018). bitHERO: Um Jogo para Auxílio no Aprendizado de Circuitos Digitais. Paper presented at the Brazilian Symposium on Computers in Education (Simpósio Brasileiro de Informática na Educação-SBIE).

Santos, R. P., \& Costa, H. A. X. (2006). Análise de Metodologias e Ambientes de Ensino para Algoritmos, Estruturas de Dados e Programação aos iniciantes em Computação e Informática. 5(1), 41-50.

Silva, E. L., \& Cunha, M. V. (2002). A formação profissional no século XXI: desafios e dilemas. 31(3).

Vahid, F. (2009). Sistemas Digitais: Bookman Editora. 